\title{
How useful are complete blood count and reticulocyte reports to clinicians in Addis Ababa hospitals, Ethiopia?
}

Misganaw Birhaneselassie ${ }^{1 *}$, Asaye Birhanu², Amha Gebremedhin ${ }^{3}$ and Aster Tsegaye ${ }^{2}$

\begin{abstract}
Background: Complete blood count (CBC) and reticulocyte (Retics) are routine hematology tests useful for the differential diagnosis of anemia and other medical conditions. However, it has been presumed that they are not used as regular as they should be in medical practice in Addis Ababa hospitals.
\end{abstract}

Methods: A hospital-based cross-sectional questionnaire survey was conducted during November-December 2010, in which 408 clinicians participated and their response on the use of CBC and Retics was assessed. The always/ frequently (A/F) response was considered to reflect routine use of the CBC/Retics parameters by the clinicians. The Chi square test was used to study statistical associations among different variables.

Result: Only four of 13 parameters in CBC were frequently or always used by more than $85 \%$ of the clinicians. Health Officers were observed to use 12 of the 13 CBC parameters less than the other professional group; interns and residents demonstrated highest use of CBC results. More than a third of clinicians' preferred white blood cell (WBC) differential report in percentages than the more useful absolute number report. Reticulocyte parameters were not being used by majority of clinicians in patient management. Clinicians rated 'average' regarding the adequacy of clinical laboratory methods course they took during medical education. As service users, clinicians indicated $\mathrm{mm}^{3}$ as unit of preference in cell count on the laboratory report form.

Conclusion: Overall, most clinicians do not use much of the data provided on routine CBC report. Additional research is needed to understand the issue further. Responsible bodies should promote the appropriate use of $\mathrm{CBC} /$ Retics reports by clinicians.

Keywords: Complete blood count, Reticulocyte count, Differential leukocyte count, Clinicians, Laboratory report form, Clinical laboratory methods course

\section{Background}

Clinical information obtained from laboratory tests play a key role in the diagnosis and management of patients [1]. A number of studies have shown that although physicians commonly request laboratory tests, they tend to use them for the wrong purposes, and ignore or misinterpret the results; such improper utilization and interpretation have obvious implications for the quality of patient care, and the economy as a whole $[2,3]$.

\footnotetext{
*Correspondence: misganawbs@gmail.com

1 Department of Medical Laboratory Sciences, Hawassa University College of Medicine and Health Science, Hawassa, Ethiopia

Full list of author information is available at the end of the article
}

The complete blood count $(\mathrm{CBC})$ and reticulocyte (Retics) parameters are hematologic tests essential in the diagnostic workup of a broad variety of clinical conditions, mainly in the differential diagnosis of anemia and related disorders [4] which are commonly seen in Addis Ababa hospitals [5]. A study on women of reproductive age in Ethiopia reported that the leading causes of anemia are iron and vitamin B12 deficiency and chronic infections [5].

Clinicians do not always use objective data effectively, and the practice can potentially lead to increases in care costs as well as mortality and morbidity [6]. However, it is possible to correct flawed decision making due to inappropriate data utilization by a variety of approaches

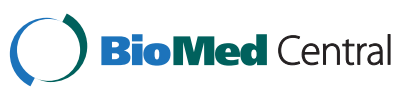


such as improving the laboratory form design, clinicians' education in laboratory based course, and implementing feedbacks from clinicians $[3,7,8]$.

In Ethiopia no documented data exists regarding the use and interpretation of hematological parameters in clinical practice. In addition, feedback of physicians on appropriateness of the $\mathrm{CBC}$ report design and the educational background of clinicians in laboratory based course has not been studied. This study aims at ascertaining the extent of use of $\mathrm{CBC} /$ Retics results, and feedback of clinicians on $\mathrm{CBC}$ in Addis Ababa hospitals.

\section{Methods}

A cross-sectional, questionnaire-based survey was conducted in Addis Ababa hospitals in November and December 2010. Clinicians involved in the diagnosis and treatment of patients in Addis Ababa hospitals, including interns, residents, health officers (*HO), general practitioners (GP), and specialists participated in the survey. Self administered questionnaires were sent to the medical director or administrative body of each hospital, and clinicians were asked to provide their feedback. ["HO: Health Officers in Ethiopia are medical graduates who undertake promotive, preventive, curative and rehabilitative services compatible to the needs of the population; are public health oriented and have less years of training than medical doctors].

The questionnaire used in the survey asked physicians to rate the frequency of use of each component of the $\mathrm{CBC} /$ differential and reticulocyte reports for patient management. Items included in a $\mathrm{CBC}$ test report were white blood cell count (WBC), WBC differential, hemoglobin (HGB), hematocrit (HCT), red blood cell (RBC) count, mean cell volume $(\mathrm{MCV})$, mean cell hemoglobin $(\mathrm{MCH})$, mean cell hemoglobin concentration $(\mathrm{MCHC})$, red cell distribution (RDW), platelet (PLT) count, mean platelet volume (MPV), platelet distribution width (PDW) and morphologic comments on RBC and WBC. [Various automated hematology analyzers of different manufacturers are used in Addis hospitals: Cell Dyn 1800 and Sysmex are used commonly for CBC; Abbot Cell Dyn 3200, Beckman Coulter LH 500 and Sysmex-2000 xi are used for CBC and Retics]. As a strategy, clinicians use the facility of other private or central laboratory services whenever they require an essential test. Reticulocyte reports included were the reticulocyte percentage, reticulocyte absolute count, reticulocyte production index (RPI) and the corrected reticulocyte count.

Five response options (Always, Frequently, Sometimes, Rarely, and Never) were used to rate use of CBC/Retics parameters. The always/frequently response was considered to be adequate or to reflect routine use of the $\mathrm{CBC} /$ Retics parameter by the clinicians. Physicians were also asked to indicate their preferences of differential reports either in percent, absolute count or both, and provide their opinion about the amount of data contained in the CBC reports (too little, too much, or just right), and preferred unit of measurement in cell count. Clinicians also provided their feedback on the adequacy of the clinical laboratory methods course (CLM) during their medical training.

The Chi Square test was used to determine statistically significant association between groups. SPSS statistical package version 17 was used for data analysis. The study proposal was defended in the school of Medical Laboratory Sciences and approved by the Institutional Review Board (IRB) of Addis Ababa University, School of Medicine. The Addis Ababa Health Bureau, the administration and the Medical Director Office of the hospitals were requested for permission and cooperation to conduct the survey. Individual consent was obtained from all participants.

\section{Result}

\section{Study participants}

The survey assessed the frequency of use of $\mathrm{CBC}$ and reticulocyte reports by a total of 408 clinicians from 34 public and private hospitals in Addis Ababa. The response rate was $100 \%$. Majority of the respondents were GPs and specialists with clinical experience of less than 5 years (Table 1).

Table 1 Distribution of study participants in Addis Ababa hospitals, from Nov 2010-Dec 2010

\begin{tabular}{|c|c|c|}
\hline Category of participants & Frequency & Percentage \\
\hline \multicolumn{3}{|l|}{ Institution ( $n=48$ ) } \\
\hline Private & 126 & $31 \%$ \\
\hline Government & 282 & $69 \%$ \\
\hline \multicolumn{3}{|l|}{ Profession $(n=408)$} \\
\hline$* \mathrm{HO}$ & 97 & $24 \%$ \\
\hline GP & 128 & $31 \%$ \\
\hline Specialist & 120 & $29 \%$ \\
\hline Intern & 13 & $3 \%$ \\
\hline Resident & 50 & $12 \%$ \\
\hline \multicolumn{3}{|c|}{ Years of experience $(n=408)$} \\
\hline$<5$ yrs & 234 & $58 \%$ \\
\hline $6-10$ yrs & 75 & $18 \%$ \\
\hline$>10$ yrs & 99 & $24 \%$ \\
\hline \multicolumn{3}{|l|}{ Specialty $(n=120)$} \\
\hline Int Medicine & 33 & $28 \%$ \\
\hline Gyn-Obs & 28 & $24 \%$ \\
\hline Surgery & 15 & $13 \%$ \\
\hline Pediatrics & 24 & $20 \%$ \\
\hline Others* & 20 & $15 \%$ \\
\hline
\end{tabular}

*HO: Health Officers.

*Others: Specialists working in other areas of specialty other than listed. 


\section{Complete blood count}

Only 4 of the 13 parameters in the $\mathrm{CBC}$ (hemoglobin, haematocrit, WBC count, and WBC differential) were frequently or always used by more than $85 \%$ of the physicians (Table 2). Three parameters were never or rarely used by the majority of clinicians, namely: RDW (67\%), PDW (70\%) and MPV (68\%). Interns and resident doctors used most of the $\mathrm{CBC}$ parameters more frequently than the other professional categories. HO's showed lesser ratings to more component of the $\mathrm{CBC}(12 / 13)$ than the other professional group.

WBC differential was reported to be used always or frequently by $90 \%$ of the clinicians. Slightly less than half of the clinicians (46\%) preferred WBC differential to be reported in absolute numbers and percentages, 39\% in percentages only and $15 \%$ in absolute numbers only.

Some of $\mathrm{CBC}$ parameters have significant association among the professional group: $\mathrm{RBC}(\mathrm{p}<0.001), \mathrm{MCV}(\mathrm{p}<$ $0.001), \mathrm{MCH}(\mathrm{p}<0.001)$, PLT $(\mathrm{p}<0.001), \mathrm{MCHC}(\mathrm{P}<0.01)$ and RDW ( $\mathrm{p}<0.05)$. There is also significant association among the specialties and use of RBC $(\mathrm{p}<0.01), \mathrm{MCHC}$ $(\mathrm{P}<0.05)$, and $\mathrm{MCV}, \mathrm{MCH}(\mathrm{p}<0.001)$. Internists highly rated use of $\mathrm{CBC}$ parameters than the other specialist counterpart (Table 3).

\section{Reticulocyte count}

Most clinicians rated use of reticulocyte parameters, rarely or never. Out of the clinicians who use the parameter, $52 \%$ preferred to receive the reports as percentages while $41 \%$ preferred absolute numbers (Table 4 ).

\section{Feedback of clinicians and adequacy of CLM course}

Majority of the clinicians preferred $\mathrm{mm}^{3}$ as units of measurement of cell count. Regarding the amount of data on the $\mathrm{CBC}$ laboratory report, most (66\%) of the clinicians reported it is 'just right'; $11 \%$ of them responded as 'too little'. Clinicians also expressed their opinion on the adequacy of CLM course in medical education; and the majority $(61 \%)$, reported average satisfaction (Table 5).

\section{Discussion}

This study showed that the use of $\mathrm{CBC}$ and reticulocyte results for clinical decision making in patient management in Addis Ababa hospitals was inadequate. The study also identified several patterns of $\mathrm{CBC} /$ Retics use that might help in the design of computerized laboratory reports and laboratory information system (LIS) in Ethiopia.

\section{Complete blood count}

The red cell indices: The study indicated that HCT and HGB were the most frequently used red cell measurements by the majority of clinicians. Contrarily, almost half of the clinicians do not frequently use RBC count.
Other studies have also reported that RBC count is not used commonly in decision making [9].

$\mathrm{MCV}, \mathrm{MCH}, \mathrm{MCHC}$ and RDW are important in the differential diagnosis of anemia. In this survey it was found that the use of $\mathrm{MCH}$ and $\mathrm{MCHC}$ was low similarly in other studies $[4,10]$. MCV is regarded as the single most useful and critical erythrocyte index in the evaluation of anemia $[9,10]$. Nevertheless, this survey revealed that only a third of the clinicians used this key parameter frequently in the classification of anemia. It is a daily practice to treat anemia in Addis Ababa hospitals [5], and despite the fact that the first step in approaching anemia is to classify the process as microcytic, normocytic or macrocytic using this valuable diagnostic tool, clinicians in Addis Ababa have differently very low use of the MCV $[4,10]$.

RDW was found to be used even much less frequently compared with other red cell indices. In another study, it has been shown that the majority of the clinicians [10] reported to use RDW always or frequently; however, it has been also reported that RDW is a largely overlooked parameter [11].

Among the professionals, interns and residents demonstrated a highest rate of use which is assumed more of superfluous $[7,12]$. MCV was rated to be used by $38 \%$ of Specialists $>28 \%$ of GPs and $>16 \%$ of HOs. RDW was reported to be used highest by specialists $(15 \%)>$ GPs $(11 \%)>$ HOs $(2 \%)$. This difference can be because specialists are geared to look for differential diagnoses; which orient them toward laboratory workups [12] than GPs and HOs [13,14]. Moreover, MCV was used more frequently in internal medicine departments as internists tend to treat more cases of anemia and other internal disorders compared to specialists in other categories.

\section{Cell morphology comments}

Obtaining a peripheral blood smear (PBS) during the initial evaluation of anemia has been recommended by other researchers as it gives additional clues from morphologic features of RBC and WBCs which substantially enhances the initial process of differential diagnosis and provides guidance for further testing [4]. This survey found only $19 \%$ of the clinicians use RBC morphology in most of the cases, while the Sandhaus study found 52\% of the clinicians use RBC morphology always and frequently for anemia diagnosis and differentiation [10].

\section{Platelet parameters}

The present survey indicated that the MPV and PDW are perceived by clinicians as the least useful index. Only less than $10 \%$ of the clinicians reported that they use the MPV or PDW frequently or always in medical practice. In spite of the clinical benefits of platelet parameters, 
Table 2 Rate of use of CBC parameters by profession in Addis Ababa hospitals Nov 2010-Dec 2010

\begin{tabular}{|c|c|c|c|c|c|c|c|c|c|c|c|c|c|c|c|c|c|c|c|c|c|c|c|c|c|c|}
\hline \multirow[b]{2}{*}{ Profession } & \multicolumn{2}{|c|}{ RBC count } & \multicolumn{2}{|c|}{ HGB } & \multicolumn{2}{|c|}{ HCT } & \multicolumn{2}{|c|}{ MCV } & \multicolumn{2}{|c|}{$\mathrm{MCH}$} & \multicolumn{2}{|c|}{$\mathrm{MCHC}$} & \multicolumn{2}{|c|}{ RDW } & \multicolumn{2}{|c|}{ Cell morphology } & \multicolumn{2}{|c|}{ PLT count } & \multicolumn{2}{|c|}{ MPV } & \multicolumn{2}{|c|}{ PDW } & \multicolumn{2}{|c|}{ WBC count } & \multirow{2}{*}{$\frac{\text { WBC }}{\text { F/A }}$} & \multirow{2}{*}{$\begin{array}{l}\text { Diff } \\
R / N\end{array}$} \\
\hline & F/A & $\mathrm{R} / \mathrm{N}$ & F/A & $\mathrm{R} / \mathrm{N}$ & F/A & $\mathrm{R} / \mathrm{N}$ & F/A & $\mathrm{R} / \mathrm{N}$ & F/A & $\mathrm{R} / \mathrm{N}$ & F/A & $\mathrm{R} / \mathrm{N}$ & F/A & $\mathrm{R} / \mathrm{N}$ & $\mathrm{F} / \mathrm{A}$ & $R / N$ & F/A & $\mathrm{R} / \mathrm{N}$ & F/A & $\mathrm{R} / \mathrm{N}$ & F/A & $\mathrm{R} / \mathrm{N}$ & F/A & $\mathrm{R} / \mathrm{N}$ & & \\
\hline $\mathrm{GP}(\mathrm{n}=128)$ & 59 & 19 & 91 & $<1$ & 90 & 2 & 28 & 24 & 24 & 29 & 22 & 32 & 11 & 66 & 15 & 23 & 63 & 8 & 10 & 69 & 12 & 67 & 98 & $<1$ & 96 & 0 \\
\hline $\mathrm{HO}(\mathrm{N}=97)$ & 41 & 14 & 73 & 2 & 77 & 3 & 16 & 2 & 13 & 45 & 12 & 47 & 2 & 74 & 19 & 31 & 39 & 24 & 5 & 68 & 3 & 77 & 87 & 0 & 81 & 5 \\
\hline Intern $(n=15)$ & 77 & 15 & 100 & 0 & 92 & 0 & 39 & 0 & 31 & 0 & 31 & 8 & 15 & 62 & 23 & 8 & 92 & 8 & 15 & 62 & 15 & 62 & 100 & 0 & 85 & 15 \\
\hline Resident $(n=50)$ & 64 & 10 & 94 & 0 & 98 & 0 & 50 & 16 & 44 & 18 & 32 & 32 & 8 & 56 & 30 & 28 & 72 & 8 & 10 & 62 & 6 & 58 & 94 & 2 & 96 & 2 \\
\hline Specialist $(n=120)$ & 43 & 29 & 89 & 3 & 93 & $<1$ & 38 & 29 & 35 & 30 & 33 & 31 & 15 & 68 & 19 & 26 & 58 & 9 & 12 & 73 & 11 & 73 & 93 & 0 & 88 & 0 \\
\hline All $(n=408)$ & 52 & 20 & 87 & 2 & 89 & 1 & 31 & 28 & 27 & 31 & 24 & 35 & 10 & 67 & 19 & 26 & 58 & 12 & 10 & 68 & 9 & 70 & 93 & $<1$ & 90 & 2 \\
\hline
\end{tabular}

F/A, (Frequently or always use); RN (rarely or never use).
Response rates are given in percentages. The "sometimes" response rate (not shown) can be calculated by using the following equation: 100\%-[F/A + R/N].

Response rates are given in percentages. The "sometimes" response rate (not shown) can be calculated by using the following equation: $100 \%-[F / A+R / N]$.
WBC: white blood cell, RBC: red blood cell, HGB: hemoglobin, HCT: hematocrit, MCV: mean cell volume, $\mathbf{M C H}$ : mean cell hemoglobin, MCHC: mean cell hemoglobin concentration, RDW: Red cell distribution width, WBC: white blood cell, RBC: red blood cell, HGB: hemoglobin, HCT: hematocit, 
Table 3 Rate of use of CBC parameters by specialty in Addis Ababa hospitals, Nov 2010-Dec 2010 ( $N=120)$

\begin{tabular}{|c|c|c|c|c|c|c|c|c|c|c|c|c|c|c|c|c|c|c|c|c|c|c|c|c|c|c|}
\hline \multirow[b]{2}{*}{ Specialty } & \multicolumn{2}{|c|}{ RBC count } & \multicolumn{2}{|c|}{ HGB } & \multicolumn{2}{|c|}{ HCT } & \multicolumn{2}{|c|}{ MCV } & \multicolumn{2}{|c|}{$\mathrm{MCH}$} & \multicolumn{2}{|c|}{$\mathrm{MCHC}$} & \multicolumn{2}{|c|}{ RDW } & \multicolumn{2}{|c|}{ Cell morphology } & \multicolumn{2}{|c|}{ PLT count } & \multicolumn{2}{|c|}{ MPV } & \multicolumn{2}{|c|}{ PDW } & \multicolumn{2}{|c|}{ WBC count } & \multirow{2}{*}{$\frac{\text { WBC }}{F / A}$} & \multirow{2}{*}{$\begin{array}{l}\text { Diff } \\
R / N\end{array}$} \\
\hline & F/A & $R / N$ & F/A & $\mathrm{R} / \mathrm{N}$ & F/A & $\mathrm{R} / \mathrm{N}$ & F/A & $\mathrm{R} / \mathrm{N}$ & F/A & $\mathrm{R} / \mathrm{N}$ & F/A & $\mathrm{R} / \mathrm{N}$ & F/A & $\mathrm{R} / \mathrm{N}$ & F/A & $R / N$ & F/A & $\mathrm{R} / \mathrm{N}$ & $\mathrm{F} / \mathrm{A}$ & $\mathrm{R} / \mathrm{N}$ & F/A & $\mathrm{R} / \mathrm{N}$ & F/A & $R / N$ & & \\
\hline Gyn-Obs $(n=28)$ & 25 & 43 & 93 & 7 & 96 & 0 & 15 & 56 & 14 & 54 & 11 & 56 & 7 & 93 & 19 & 35 & 36 & 18 & 11 & 86 & 7 & 93 & 82 & 0 & 71 & 0 \\
\hline Int Medicine $(n=34)$ & 73 & 12 & 97 & 0 & 100 & 0 & 73 & 9 & 67 & 9 & 58 & 12 & 24 & 49 & 31 & 13 & 88 & 3 & 21 & 58 & 22 & 50 & 100 & 0 & 100 & 0 \\
\hline Surgery $(n=15)$ & 40 & 27 & 100 & 0 & 93 & 0 & 27 & 33 & 20 & 40 & 27 & 40 & 13 & 67 & 0 & 43 & 60 & 7 & 13 & 60 & 13 & 67 & 100 & 0 & 100 & 0 \\
\hline Pediatrics $(n=24)$ & 33 & 33 & 70 & 4 & 88 & 0 & 42 & 12 & 46 & 17 & 46 & 17 & 21 & 50 & 8 & 8 & 42 & 12 & 4 & 75 & 4 & 75 & 96 & 0 & 92 & 0 \\
\hline Others $(n=20)$ & 35 & 35 & 85 & 5 & 85 & 5 & 10 & 40 & 10 & 40 & 10 & 40 & 5 & 85 & 25 & 45 & 60 & 5 & 5 & 85 & 5 & 85 & 85 & 0 & 75 & 0 \\
\hline All $(n=120)$ & 43 & 29 & 89 & 3 & 93 & $<1$ & 38 & 29 & 35 & 30 & 33 & 31 & 15 & 67 & 19 & 26 & 58 & 9 & 12 & 72 & 11 & 73 & 93 & 0 & 88 & 0 \\
\hline
\end{tabular}

F/A, (Frequently or always use); RN (rarely or never use). Response rates are given in percentages. The "sometimes" response rate (not shown) can be calculated by using the following equation: $100 \%-[F / A+R / N]$.
WBC: white blood cell, RBC: red blood cell, HGB: hemoglobin, HCT: hematocrit, $\mathbf{M C V}$ : mean cell volume, MCH: mean cell hemoglobin, MCHC: mean cell hemoglobin concentration, RDW: Red cell distribution width,

PLT: plate let, MPV: mean platelet volume, PDW: Platelet distribution width. 
Table 4 Rate of use of reticulocyte parameters by clinicians in Addis Ababa hospitals, Nov 2010-Dec 2010 ( $\mathrm{n}=408$ )

\begin{tabular}{|c|c|c|c|c|c|c|c|c|}
\hline \multirow[t]{2}{*}{ Profession } & \multicolumn{2}{|c|}{ Retics \% } & \multicolumn{2}{|c|}{ Retics Abs } & \multicolumn{2}{|l|}{ RPI } & \multicolumn{2}{|c|}{ Corrected Retics } \\
\hline & $A / F$ & $\mathrm{R} / \mathrm{N}$ & $A / F$ & $\mathrm{R} / \mathrm{N}$ & $A / F$ & $\mathrm{R} / \mathrm{N}$ & $A / F$ & $\mathrm{R} / \mathrm{N}$ \\
\hline$G P(n=128)$ & 8 & 41 & 7 & 59 & 4 & 75 & 2 & 74 \\
\hline $\mathrm{HO}(\mathrm{n}=97)$ & 9 & 66 & 5 & 68 & 4 & 84 & 5 & 79 \\
\hline Intern $(n=13)$ & 23 & 23 & 15 & 23 & 0 & 31 & 8 & 39 \\
\hline Resident $(n=50)$ & 10 & 40 & 8 & 44 & 6 & 64 & 6 & 60 \\
\hline Specialist $(n=120)$ & 10 & 47 & 5 & 64 & 3 & 77 & 2 & 75 \\
\hline Total $(n=408)$ & 10 & 48 & 7 & 59 & 4 & 75 & 4 & 72 \\
\hline
\end{tabular}

F/A, (frequently or always use); R/N, (rarely or never use). Response rates are given in percentages. The "sometimes" response rate (not shown) can be calculated by using the following equation: $100 \%-[\mathrm{F} / \mathrm{A}+\mathrm{R} / \mathrm{N}]$.

the contribution of the MPV and PDW to clinical practice in Addis Ababa hospitals was low.

\section{WBC count, WBC differential and unit of reporting}

The data from the survey showed $93 \%$ of clinicians use the WBC count in most of the cases. Likewise, $90 \%$ of the clinicians use the WBC differential mostly in medical practice. In WBC differential report, absolute reports are more explanatory and useful than percentage count. The present study showed that more than a third of the clinicians prefer percentages of WBC differential than the more useful absolute numbers. This indicates that a significant number of the clinicians interpret differential reports incorrectly, and may not be obtaining the valuable information required, which could mislead diagnosis.

\section{Table 5 Feedback of clinicians in Addis Ababa hospitals on CBC and adequacy of CLM course from Nov 2010- Dec 2010}

\begin{tabular}{lcc}
\hline Parameter & Frequency & Percent (\%) \\
\hline CBC content & & \\
$(\mathrm{n}=399)$ & 262 & $66 \%$ \\
Just right & 91 & $23 \%$ \\
Too much & 46 & $11 \%$ \\
Too little & & \\
Unit for cell count & & \\
( $\mathrm{n}=396)$ & 264 & $66 \%$ \\
Per mm & & \\
Per $\mu \mathrm{L}$ & 110 & $28 \%$ \\
Per $\mathrm{L}$ & 22 & $6 \%$ \\
Adequacy of CLM course & & \\
( $\mathrm{n}=391)$ & & $32 \%$ \\
Excellent and very good & 127 & $58 \%$ \\
Good and fair & 226 & $10 \%$ \\
Poor and bad & 38 & \\
\hline
\end{tabular}

\section{Reticulocyte count}

The use of the reticulocyte parameter in Addis Ababa hospitals is quite low. Lack of hematology analyzers that perform both $\mathrm{CBC}$ and Retics in most hospitals can largely limit Retics use; yet as a strategy clinicians could use extra laboratory services when additional investigations are required. The use of reticulocyte count as percentage and absolute unit assessed from the frequency of use of reticulocyte parameter indicated that slightly more than half of the clinicians claimed to use reticulocyte count in percentage units. Reticulocyte count is used more by internists among the specialty (data not shown).

\section{Feedback of clinicians on complete blood count}

Units of measurement: Cell counts such as RBC, PLT and WBC can be reported per $\mathrm{mm}^{3}$, per $\mu \mathrm{L}$, or per $\mathrm{L}$. This study showed that most of the clinicians prefer cell count to be reported in $\mathrm{mm}^{3}$ unit. This implies that emphasis should be given in the reporting systems during medical training thus clinicians are well acquainted with the use of the international standard (SI) measurement units $[15,16]$.

\section{Amount of data}

Most clinicians suggested the amount of data in the hematology $\mathrm{CBC}$ report was just right. Only about one in ten respondents mentioned that the amount of data was inadequate and most of these were internists. This phenomenon was also reflected in internists' frequent use of reticulocyte reports, which further suggests that there is a need for additional laboratory tests for use by a segment of medical specialties (internists). Although more dozens of hematology parameters useful for patient management are not part of the $\mathrm{CBC}$ reports of Addis Ababa hospitals, majority of the clinicians are satisfied with the limited $\mathrm{CBC}$ parameters available from the common hematology analyzers. In fact use of more advanced parameters parallels expansion of the health standard and service within the country. 


\section{Clinical laboratory methods course}

The results of this study indicated that most clinicians were not satisfied with the quality of their CLM course, although more than a quarter rated it as 'excellent' or 'very good'. This shows that there is room for improvement in the course, both in terms of quality and quantity of materials covered.

\section{Conclusion}

$\mathrm{CBC} /$ reticulocyte parameters are important hematological tests used routinely in clinical decision making mainly in relation to anemia and blood disorders. However, the use of $\mathrm{CBC} /$ Retics parameters in the clinicians surveyed in Addis Ababa hospitals is found to be inadequate. The study suggested that laboratory based medical course (CLM), and content of a $\mathrm{CBC}$ report form contributed to the low use rate of these parameters. Responsible bodies should intervene and promote adequate use of $\mathrm{CBC} /$ Retics parameters in medical practice. Further research is needed to identify the main causes of the low use rate of $\mathrm{CBC} /$ Retics reports by clinicians.

\section{Competing interests}

The authors declare that they have no competing interests.

\section{Authors' contributions}

$M B$ was the principal investigator for the study; $M B, A B, A G$ and $A T$ contributed to the design of the study. MB carried out the data collection; $A B$ and $A T$ supervised data collection; $M B, A G$ and $A T$ interpreted the result; all authors approved the final manuscript.

\section{Acknowledgements}

Our special thanks go to Dr. Tamer Abdelrahman and Dr. Eskindir Loha for their valuable contribution in the statistical analysis of the research. We would like to thank the School of Graduate Studies, Addis Ababa University for financial support of the study. We also acknowledge the clinicians participated in the survey.

\section{Author details}

'Department of Medical Laboratory Sciences, Hawassa University College of Medicine and Health Science, Hawassa, Ethiopia. ${ }^{2}$ School of Medical Laboratory Science, Addis Ababa University College of Health Science, Addis Ababa, Ethiopia. ${ }^{3}$ Department of Internal Medicine, Addis Ababa University Medical Faculty, Addis Ababa, Ethiopia.

Received: 12 March 2013 Accepted: 5 December 2013

Published: 11 December 2013

\section{References}

1. Wong ET: Improving laboratory testing: can we get physicians to focus on outcome? Clin Chem 1995, 41(8):1241-1247.

2. Jackson BR: Managing laboratory test use: principles and tools. Clin Lab Med 2007, 27(4):733-748.

3. van Walraven C, Goel V, Chan B: Effect of population-based interventions on laboratory utilization: a time-series analysis. JAMA 1998, 280(23):2028-2033.

4. Tefferi A, Hanson CA, Inwards DJ: How to interpret and pursue an abnormal complete blood cell count in adults. Mayo Clin Proc 2005, 80(7):923-959.

5. Haidar JA, Pobocik RS: Iron deficiency anemia is not a rare problem among women of reproductive ages in Ethiopia: a community based cross sectional study. BMC Blood Disord 2009, 9:7.

6. Altshuler $\mathrm{CH}$ : Data utilization, not data acquisition, is the main problem. Clin Chem 1994, 40:1616-1620.
7. Peterson SE, Rodin AE: Prudent laboratory usage, cost containment, and high quality medical care: are they compatible? Hum Pathol 1987, 18(2):105-108.

8. Wilson ML: Educating medical students in laboratory medicine. Am J Clin Pathol 2010, 133(4):525-535.

9. Ward PC: The $C B C$ at the turn of the millennium: an overview. Clin Chem 2000, 46(8):1215-1220.

10. Sandhaus $L M$, Meyer $P$ : How useful are $C B C$ and reticulocyte reports to clinicians? Am J Clin Pathol 2002, 118(5):787-793.

11. Perlstein TS, Weuve J, Pfeffer MA, Beckman JA: Red blood cell distribution width and mortality risk in a community-based prospective cohort. Arch Intern Med 2009, 169(6):588-594.

12. Moskowitz MA: A clinician's view of laboratory utilization. MLO Med Lab Obs 1984, 16(7):51-57.

13. Federal Ministry of Education and Ministry of Health of Ethiopia: Curriculum for generic and post basic accelerated health officers training program. Addis Ababa, Ethiopia: Federal Ministry of Education and Ministry of Health of Ethiopia; 2005

14. Mozes $B$, Haimi-Cohen $Y$, Halkin H: Yield of the admission complete blood count in medical inpatients. Postgrad Med J 1989, 65(766):525-532.

15. Rempher KJ, Little J: Assessment of red blood cell and coagulation laboratory data. AACN Clin Issues 2004, 15(4):622-637.

16. Young DS: Implementation of SI unit for clinical laboratory data. Ann Intern Med 1987, 106:114-129.

doi:10.1186/2052-1839-13-11

Cite this article as: Birhaneselassie et al:: How useful are complete blood count and reticulocyte reports to clinicians in Addis Ababa hospitals, Ethiopia? BMC Hematology 2013 13:11.

\section{Submit your next manuscript to BioMed Central and take full advantage of:}

- Convenient online submission

- Thorough peer review

- No space constraints or color figure charges

- Immediate publication on acceptance

- Inclusion in PubMed, CAS, Scopus and Google Scholar

- Research which is freely available for redistribution 